\title{
Low prevalence of eyelid infestation by Demodex folliculorum in patients with primary open-angle glaucoma treated with prostaglandin analogues
}

\section{Baja prevalencia de infestación palpebral por Demodex folliculorum en pacientes con glaucoma primario de ángulo abierto tratados con análogos de prostaglandinas}

Fernando Pólitt ${ }^{1,2 *}$, Andrés Pólit ${ }^{3}$ and Nicolás Molano ${ }^{4}$

${ }^{1}$ Hospital Clínica Kennedy; ${ }^{2}$ Clínica Internacional de la Visión de Ecuador. Guayaquil, Ecuador; ${ }^{3}$ Escuela Superior de Oftalmología, Instituto Barraquer de América, Bogotá, Colombia; ${ }^{4}$ Bueri Stats SAS. Bogotá, Colombia

\begin{abstract}
Introduction: Primary open-angle glaucoma (POAG) shows an exponential growth related to age. Prostaglandin analogues are first-line drugs. As a side effect, they cause elongation, pigmentation and thickening of the eyelashes. Demodex are ectoparasites that live in the skin of humans and are associated to blepharitis. Their rate of infestation increases with age. Aim: Analyze and compare the prevalence of eyelid infestation by Demodex in patients with POAG who attend the clinic in a random manner, and who are receiving treatment with prostaglandin analogues. Methods: 110 eyes treated with prostaglandin analogues for POAG were included. An eyelash was removed to analyze it under the microscope and observe the presence of infestation. The results were compared with a group of patients with similar characteristics who did not use this drug. In addition, an in vitro study with one drop of different prostaglandin analogues on a slide of samples infested with Demodex was carried out to evaluate the direct chemical effect. Results: $36.4 \%$ of patients with POAG treated with prostaglandin analogues were infested with Demodex. The in vitro study showed the morphological changes that the mites suffered. Conclusions: Although the average age was high in the group of patients studied, a low prevalence of Demodex eyelid infestation was observed, unlike other series of patients of the same age who did not receive this medication and had a higher prevalence of infestation.
\end{abstract}

Key words: Glaucoma. Prostaglandin analogues. Demodex. Blepharitis.

\section{Resumen}

Introducción: El glaucoma primario de ángulo abierto (GPAA) muestra un crecimiento exponencial relacionado con Fa edad. Los análogos de prostaglandinas son los medicamentos de primera elección. Como efecto secundario provocan alargamiento, pigmentación y engrosamiento de las pestañas. El Demodex es el ectoparásito que se encuentra en la piel de los humanos y se asocia a blefaritis. Su tasa de infestación aumenta con la edad. Objetivo: Analizar y comparar la prevalencia de infestación

Correspondence:

*Fernando Pólit-Huerta

Hospital Clínica Kennedy Samborondón

Vía la Puntilla-Samborondón km 2.5

Torre Beta 40 Of. 402

Date of reception: 06-09-2017

Date of acceptance: 01-03-2018

DOI: 10.24875/RMOE.M18000015
Available online: 14-05-2018 Rev Mex Oftalmol(Eng).2018;92(3):122-130 www.rmo.com.mx the CC BY-NC-ND 
palpebral por Demodex en pacientes de edad avanzada con GPAA, que acuden a la consulta de manera aleatoria y que estaban recibiendo tratamiento con análogos de prostaglandinas. Metodología: Se incluyeron 110 ojos en tratamiento con análogos de prostaglandinas para GPAA. Se depiló una pestaña para analizarla bajo el microscopio y observar su probable infestación. Se compararon los resultados con un grupo de pacientes adultos mayores que no usaban este medicamento. Además, se realizó un estudio in vitro con una gota de los diferentes análogos de prostaglandinas en la placa portaobjetos de muestras infestadas con Demodex, para valAORr el efecto químico directo. Resultados: El 36.4\% de pacientes con GPAA que recibían tratamiento con análogos de prostaglandinas estaban infestados por Demodex. En el estudio in vitro se observaron los cambios morfológicos que sufrieron los ácaros. Conclusiones: Aunque el promedio de edad fue elevado en el grupo de pacientes estudiados, se observó baja prevalencia de infestación palpebral por Demodex, lo cual contrasta con otras series de pacientes de la misma edad que no recibían esta medicación y en que la prevalencia de infestación fue mayor.

Palabras clave: Glaucoma. Análogos de prostaglandina. Demodex. Blefaritis.

\section{Introduction}

Primary open-angle glaucoma (POAG) is defined as a chronic and progressive optic neuropathy characterized by morphological changes in the optic nerve head or retinal nerve fiber layer and visual field deterioration, accompanied or not by ocular hypertension'. It represents one of the first causes of irreversible blindness in the world and shows an age-related exponential growth ${ }^{2}$. The topical use of prostaglandin analogues as ocular hypotensors in the control of glaucoma is considered the first treatment of choice. Prostaglandin analogues act by increasing the outflow of aqueous humor from the eye. However, its administration may be associated with periocular pigmentation, redness, mild eye irritation and darkening of the iris $^{3-5}$.

Demodex is the most common microscopic ectoparasite of the human skin $^{6}$. Its habitat in narrow places forced it to evolve into a vermiform mite. A two very sharp stilettos form its buccal apparatus, with which they cut the membranes of the epithelial cells that line the follicles. Thus, they feed from their content and from sebaceous glands. During their displacement, the claws of the legs cause abrasion in the walls of the hair follicle, which induces epithelial hyperplasia and hyperkeratinization. This induces the formation of collar-shaped structures that implant at the base of the eyelashes, called cylindrical dandruff, constituted by sebaceous residues, parasite excreta, epithelial proliferation and follicle exudates ${ }^{7}$. Its rate of infestation increases with age, and it is about 68 to $100 \%$ in the population over 60 years of age ${ }^{8}$.

Due to the fact that a high percentage of patients diagnosed with POAG are elderly, and that this age group has a high rate of Demodex folliculorum infestation in the hair follicles of the eyelashes, this study aims to understand how topical treatment with prostaglandin analogues affects the prevalence of eyelid infestation by $\mathrm{D}$. folliculorum in elderly patients. This originated from the observation of a patient who used a prostaglandin analogue in one eye, while in the other he used a combination of timolol + dorzolamide and had abundant mites on the eyelashes unlike the medicated eye with prostaglandin analogues. Another additional objective of the study was to evaluate the effect of prostaglandin analogues with an in vitro study.

\section{Materials and methods \\ Design and population}

This is a cross-sectional, observational study that analyzes the prevalence of infestation by $D$. folliculorum in elderly patients diagnosed with POAG and who were receiving treatment with prostaglandin analogues. The patients included in the study were those who attended the private ophthalmological consultation of one of the authors (FPH) between September 2011 and August 2014 at the Hospital Clínica Kennedy in Guayaquil, Ecuador. Patients who did not use the medication for at least three months were excluded. The results were then compared with those of a group of 78 eyes of 64 patients (from a previously performed study ${ }^{9}$ ) who were not receiving treatment with prostaglandin analogues.

\section{Diagnostic technique}

Each participant received a complete ophthalmological examination with a Rodenstock RO 2000 SE $^{\circledR}$ slit lamp, with emphasis on the exploration of the eyelids to identify the presence of cylindrical dandruff at the base of the eyelashes. Since the finding of cylindrical dandruff is associated with $D$. folliculorum infestation, all screening procedures in carrier patients were exhausted to confirm the existence of the parasite. At $3 \mathrm{~mm}$ from the free margin of the eyelid, the lash that had a cylindrical dandruff was firmly secured with 
tweezers. Epilation was performed with lateral movements of the tweezers, to achieve removing the lash with the complete cylindrical dandruff. During the lateral movement of the tweezers, the examiner can observe with magnification the presence of the mites in breech position in the external orifice of the hair follicle. The removed lash was placed on a slide, instilling a drop of saline and covering with the slide cover. Immediately, under the Primo Star Carl Zeiss Meditec ${ }^{\circledR}$ light microscope, the sample was scanned with magnification, which varied between 10x and 40x. The finding under a light microscope of at least one mite, whether in adult, larval or egg state, was considered a positive result. Sometimes, after epilation, it was possible to observe remains of the cylindrical dandruff in the external orifice of the hair follicle, resembling a cap. In such cases, the rest of the cylindrical dandruff was removed with fine-tipped tweezers and placed on the slide as well as the eyelash, and then a drop of saline solution was instilled. In positive cases, the number of parasites was quantified. Since Demodex usually hides in the cylindrical dandruff, we proceeded to press with the objective $100 x$ the cover slide in an effort to soften the cylindrical dandruff and release the parasites, so they could be observed under the light microscope. If the examination of an eyelash that included a cylindrical dandruff was negative, a second or third eyelash was removed. In that second or third attempt, a solution with dye was instilled, either $2 \%$ sodium fluorescein, rose bengal, green lysamin or trypan blue, which facilitated the detection of the parasite. In cases of infestation with multiple mites, they were observed as clusters.

They were so evident that it was possible to observe them after placing the plate with the sample under the slit lamp, without the need for microscopy, confirming the presence of the parasite. In patients who had cylindrical dandruff-free eyelashes, we chose to epilate a short, thin one, because small, brittle lashes usually have Demodex.

\section{In vitro study}

Patients who attended the ophthalmological consultation and who showed under the slit lamp the presence of cylindrical dandruff, a pathognomonic sign of Demodex infestation, had one of their infested eyelashes removed and observed under a light microscope. Forty-five epilated infested eyelashes were each placed on a slide; adding in 15 samples a drop of $0.03 \%$ bimatoprost (Lumigan ${ }^{\circledR}$ ); in 15 samples a drop of $0.004 \%$ travoprost $\left(\operatorname{Travatan}^{\circledR}\right)$ and in the remaining 15 samples a drop of $0.005 \%$ latanoprost $\left(\right.$ Latof $\left.^{\circledR}\right)$. The slide was observed periodically under the light microscope (Fig. 1). The number of hours that the mites presented movement of their bifid legs or their buccal apparatus (survival time) was counted. It was a requirement that the mites were not completely hidden in the cylindrical dandruff.

\section{Data management and statistical analysis}

All the information was stored in a Microsoft Access database management system (Microsoft Office ${ }^{\circledR}$ ). Some cases of clinical interest were documented with pictures of the eyelids and the anterior segment, with the Digicam photographic system adapted to a slit lamp of the Visulas 532 Carl Zeiss Meditec ${ }^{\circledR}$. In most cases, photographs of the specimens examined under the light microscope were obtained.

The descriptive statistics are calculated to describe the age and sex of the patients involved in the study, dividing the information for treated and untreated patients. The usual descriptive statistics are calculated for the eyelashes.

In order to study the statistical associations between the outcomes of interest (infestation and number of mites) and the treatment, age and sex variables, two approaches were used. The first uses bivariate statistics to measure the association of the outcomes with the variables of interest. For this approach, we used the Chi-square test (to evaluate the association between pairs of categorical variables), the nonparametric Kruskall-Wallis test (to evaluate the association between a categorical and a numerical variable) and Spearman correlation to evaluate associations between numeric variables. This approach aims to evaluate in a marginal way the associations between pairs of variables, ignoring the effect of others.

In the second approach, we used generalized mixed linear models (GLMM) (see McCulloch, et al. ${ }^{10}$ ) in order to construct regression models that allow us to study more complex relationships between the outcomes of interest and the other variables as a whole. These models allow to explicitly introduce the existing correlation between eyelashes of the same individual by adding a random effect at the level of each patient, which overcomes the disadvantage of dependent observations in the study. For the outcome of infestation, a GLMM was adjusted assuming a binomial distribution for infestation, while for the outcome of number of mites a Poisson distribution was assumed. To determine the optimal variables and interactions that explain the outcome of 


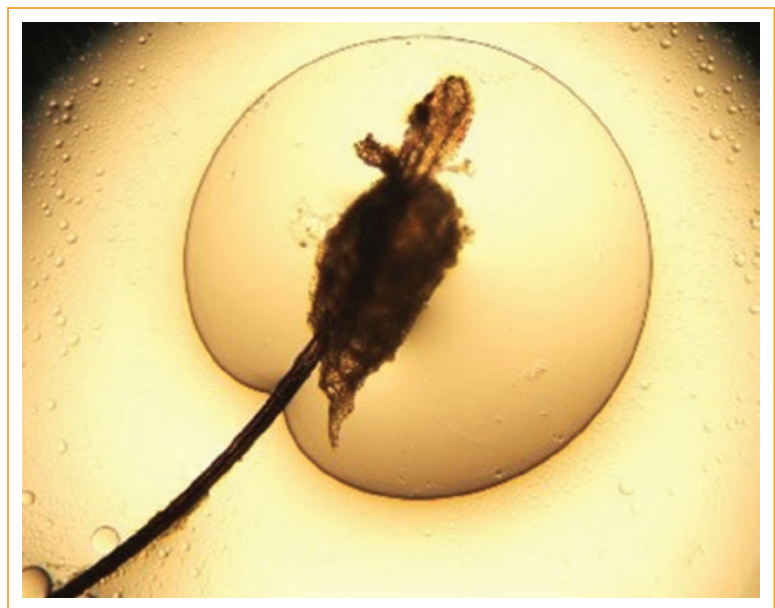

Figure 1. A drop of latanoprost on an infested eyelash without a slide cover (photograph authored by Dr. F. Pólit).

interest, several models were adjusted, and the most parsimonious model was selected based on the Akaike criterion (McCulloch, et al. $)^{10,11}$.

The statistical analyses were carried out with the statistical software $R$ version 3.3.3'2 ${ }^{12}$ GLMM were adjusted using the Ime4 package (Bates, et al. ${ }^{11}$ ).

\section{Results}

One hundred ten eyes of 62 patients were evaluated; $59 \%(n=36)$ were female (Table 1$)$. The average age was 70.1 years, with a range from 48 to 88 years; $89.1 \%$ $(n=98)$ were at least 60 years old.

The total prevalence of Demodex infestation was $36 \%(n=40)$. One hundred percent of the patients with eyelashes with cylindrical dandruff had mites. Of the 40 infested patients, 12 showed no cylindrical dandruff, but 3 of them (25\%) had squamous blepharitis, and another had meibomitis and trichiasis. The average of mites of the total population was 0.79 (range 0-5 per eyelash). Among infested patients, $15 \%(n=6)$ had at least 4 mites.

Of the 110 eyes, $52 \%(n=57)$ were controlled with latanoprost; $42 \%(n=45)$ with travoprost; and $7 \%$ $(n=8)$ with bimatoprost. The average time of continuous treatment that patients had with prostaglandin analogues was 47.9 (range 3-192) months, and $77 \%(n=85)$ had a minimum of 12 months with treatment. Fifty-four percent $(n=59)$ received a combination treatment of prostaglandin analogues with beta-blockers (timolol maleate), carbonic anhydrase inhibitors (dorzolamide) or alpha-2 adrenergic receptor agonists (brimonidine). The
Table 1. Sex and age description of the study patients. For sex, female percentage and absolute frequency are displayed. For age, mean and standard deviation (between parentheses) are presented. $P$ values correspond to Chi-square and Kruskall-Wallis tests, respectively

\begin{tabular}{|c|c|c|c|}
\hline \multirow[t]{2}{*}{ Variables } & \multicolumn{2}{|c|}{ Treatment } & \multirow[t]{2}{*}{$\mathbf{p}$} \\
\hline & Yes & No & \\
\hline Female & $58.07 \%(36)$ & $65.63 \%(42)$ & 0.49 \\
\hline Age & 70.34 (9.7) & 72.38 (9.3) & 0.19 \\
\hline $\mathrm{n}$ & 62 & 64 & $\underline{\underline{\underline{n}}}$ \\
\hline & & & $\begin{array}{l}\frac{a}{3} \\
\frac{2}{2}\end{array}$ \\
\hline
\end{tabular}

eyes treated with prostaglandin analogues presented hypertrichosis, increased thickness and pigmentation of the eyelashes and absence or minimal Demodex infestation. On the contrary, eyelashes of the contralateral eye that did not receive prostaglandin analogues showed demodex blepharitis, although in three cases they also showed lengthening of the eyelashes, but in a lesser proportion to the contralateral eye that received prostaglandin analogues (Fig. 2).

Table 1 presents the description of the patients involved in the study.

The $p$-values reported in table 1 indicate that the treated and untreated groups have similar sex and age distributions.

Next, we present the description of the eyelashes studied (Table 2).

We obtained 78 eyelashes of 64 untreated individuals and 110 eyelashes of 62 treated individuals. At eyelash level, treated and untreated groups have similar sex and age distributions $(p=0.47$ and $p=0.14$, respectively), showing the high comparability between groups. The presence of cylindrical dandruff, infestation and number of mites is much higher in the untreated group $(p<0.001)$ (Table 2).

Table 3 shows the description of the eyelashes according to their infestation status. No statistically significant associations were found between the status of infestation and demographic variables such as age and sex. The presence of cylindrical dandruff and the absence of treatments were associated with a greater frequency of infestation (Table 3).

The odds ratio $(\mathrm{OR})$ of cylindrical dandruff and treatment related to the infestation are 7.849 (95\% Cl: 3.9916.31) and 231 (95\% Cl: 28.56-7,941.20), respectively.

Table 4 shows the bivariate analysis of the number of mites related to the categorical variables.

Similar to what was previously reported for the infestation status, sex and age (Spearman correlation 0.19) 


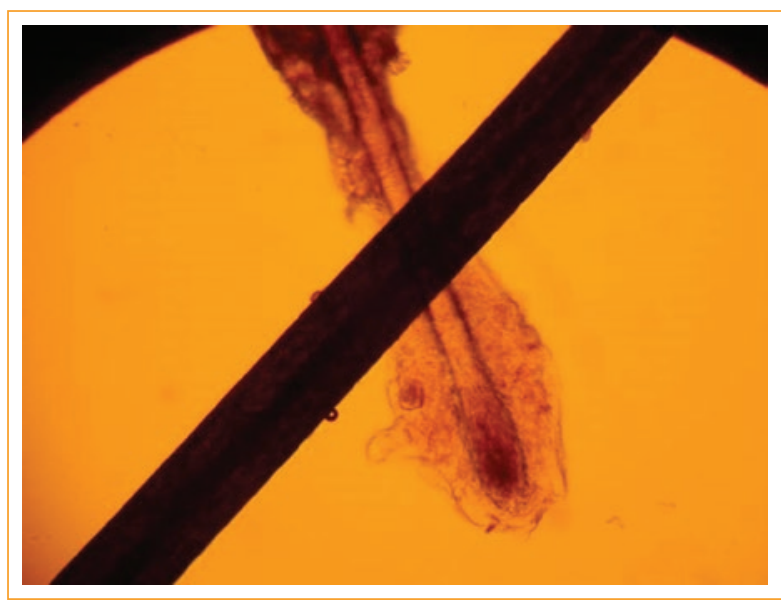

Figure 2. Two crossed eyelashes of the same patient. The upper one corresponds to the eye that received travoprost; the lower one received timolol maleate with dorzolamide (photograph authored by Dr. F. Pólit).

are not associated with the number of mites observed, while treatment significantly decreases the number of cylindrical dandruff and mites (Table 4).

\section{Generalized linear mixed model}

Next, we present the results of the GLMM applied to the outcomes of infestation and number of mites, in order to elucidate the relationship of these outcomes with age, sex and treatment.

For the analysis of infestation, we obtained a model in which the probability of infestation is explained in terms of the interaction between sex and treatment. Adjustment by age was not necessary, according to the selection of models under the Akaike criterion (Table 5).

One of the most relevant results of this analysis is the interaction between sex and treatment $(p=0.058)$. This interaction indicates that there is a differential treatment behavior depending on sex. In particular, the adjusted OR (AOR) of infestation related to treatment for males is higher than for females (AOR: 1,798; 95\% Cl: $12-275,999$ vs. AOR: 21.2; 95\% Cl: 2-222) (Table 5). This relationship is clearly observed in figure 3 .

In contrast, the GLMM for the outcome number of mites shows different results compared to the infestation outcome. For this outcome, age is more important to explain the presence of the number of mites, but sex does not provide greater explanatory power. Adjustment by sex was not necessary, according to the model selection under the Akaike criterion (Table 6).
Table 2. Description of study eyelashes by treatment status. For categorical variables, percentage and absolute frequency (between parentheses) are displayed. For continuous variables, mean and standard deviation (between parentheses) are presented. Pvalues correspond to chi-square and Kruskall-Wallis tests, respectively

\begin{tabular}{|c|c|c|c|}
\hline \multirow[t]{2}{*}{ Variables } & \multicolumn{2}{|c|}{ Treatment } & \multirow[t]{2}{*}{ p } \\
\hline & No & Yes & \\
\hline Female & $65.39 \%(51)$ & $59.09 \%(65)$ & 0.47 \\
\hline Cylindrical dandruff & $61.54 \%(48)$ & $26.36 \%(29)$ & $<0.0001$ \\
\hline Infestation & $82.05 \%(64)$ & $36.36 \%(40)$ & $<0.0001$ \\
\hline Mites & $2.83(2.68)$ & $0.74(1.34)$ & $<0.0001$ \\
\hline Age & $71.96(9.07)$ & 70.09 (9.58) & 0.14 \\
\hline$n$ & 78 & 110 & \\
\hline
\end{tabular}

Table 3. Description of study eyelashes by infestation status. For categorical variables, percentage and absolute frequency (between parentheses) are displayed. For continuous variables, mean and standard deviation (between parentheses) are presented. P values correspond to chi-square and Kruskall-Wallis tests, respectively

\begin{tabular}{|l|c|c|c|}
\hline \multirow{2}{*}{ Variables } & \multicolumn{2}{|c|}{ Infestation } \\
\cline { 2 - 4 } & Positive & Negative & \\
\hline Female & $60.58 \%(63)$ & $63.10 \%(53)$ & 0.84 \\
\hline Cylindrical dandruff & $74.04 \%(77)$ & $0 \%(0)$ & $<0.0001$ \\
\hline Without treatment & $61.54 \%(64)$ & $16.67 \%(14)$ & $<0.0001$ \\
\hline Mites & $0(0)$ & $2.90(2.33)$ & $<0.0001$ \\
\hline Age & $69.54(9.22)$ & $71.94(9.43)$ & 0.076 \\
\hline $\mathrm{n}$ & 104 & 84 & 0 \\
\hline
\end{tabular}

Table 4. Descriptive statistics of mite distribution according to the levels of categorical variables

\begin{tabular}{|l|l|l|l|}
\hline Variables & Level & Mean (si) & p \\
\hline Sex & F & $1.63(2.28)$ & 0.91 \\
& M & $1.57(2.23)$ & \\
\hline \multirow{2}{*}{ Cylindrical dandruff } & Negative & $0.69(1.49)$ & $<0.0001$ \\
& Positive & $2.92(2.52)$ & 0 \\
\hline Treatment & No & $2.83(2.68)$ & $<0.0001$ \\
& Yes & $0.74(1.34)$ & 4 \\
\hline
\end{tabular}

The results of this model are depicted in figure 4 . The effect of age on the number of mites is small; however, the difference between treated and untreated after adjusting for age is maintained. 
Table 5. Results of the generalized linear mixed model for infestation status. Left: Estimation that corresponds to the estimated parameters of the model. $p$ : $p$ value associated to the model parameter. Right: OR corresponding to evaluated conditional $O R s$, for example, $T \mid G=M$ is the treatment's $O R$ on infestation for males, and $G \mid T=N$ is gender's OR on infestation for the group without treatment. AOR: adjusted odds ratio; Lower-Upper: lower and upper limits of the $95 \%$ confidence interval; $p$ : AOR-associated $P$ value

\begin{tabular}{|l|c|c|c|c|c|c|c|}
\hline & Estimate & $\mathrm{p}$ & OR & AOR & Inferior & Superior & p \\
\hline Intercept & -1.22 & 0.14 & $\mathrm{~T} \mid \mathrm{G}=\mathrm{M}$ & 1798 & 12 & 275999 & 0.004 \\
\hline Without treatment & 7.49 & 0.004 & $\mathrm{~T} \mid \mathrm{G}=\mathrm{F}$ & 21.2 & 2.0 & 222.6 & 0.01 \\
\hline Female & 0.44 & 0.67 & $\mathrm{G} \mid \mathrm{T}=\mathrm{N}$ & 1.55 & 0.205 & 11.70 & 0.67 \\
\hline Without treatment: Female & -4.44 & 0.058 & $\mathrm{G} \mid \mathrm{T}=\mathrm{P}$ & 0.018 & 0.000 & 1.013 & 0.05 \\
\hline
\end{tabular}

Table 6. Results of the generalized linear mixed model for the number of mites. In this model, the logarithm of the average number of mites is modeled based on sex and age

\begin{tabular}{|l|c|c|c|c|}
\hline & Estimate & Inferior & Superior & $p$ \\
\hline Intercept & -0.80 & -1.26 & -0.41 & $<0.001$ \\
\hline Age & 0.03 & 0.00 & 0.05 & 0.03 \\
\hline $\begin{array}{l}\text { Without } \\
\text { treatment }\end{array}$ & 1.42 & 0.94 & 1.93 & $<0.0001$ \\
\hline
\end{tabular}

The parameter associated with the absence of treatment can be interpreted as follows:

$$
\mu_{\mathrm{Tn}} / \mu_{\mathrm{Tp}}=\exp (1.42)=4.14
$$

Where $\mu_{T n}$ and $\mu_{T p}$ are the expected number of mites for the group without and with treatment, respectively. This means that the expected number of mites in the eyelashes without prostaglandin analogues is $4.14 \mathrm{ti}-$ mes the number in the eyelashes with prostaglandin analogues.

\section{In vitro study}

One hundred percent of the Demodex observed in the 45 epilated lashes showed movements of the forked legs or the buccal apparatus at least 180 minutes after instilling a drop of prostaglandin analogues. However, as the hours passed by, the morphological changes that the mites suffered were much more noticeable compared to when a drop of saline solution was used (Fig. 5). However, there were cases in which Demodex survival reached 26 hours.

\section{Discussion}

In previous studies, it has been established that POAG shows an exponential age-related growth, and constitutes one of the first causes of non-reversible blindness globally. On the other hand, eyelid infestation

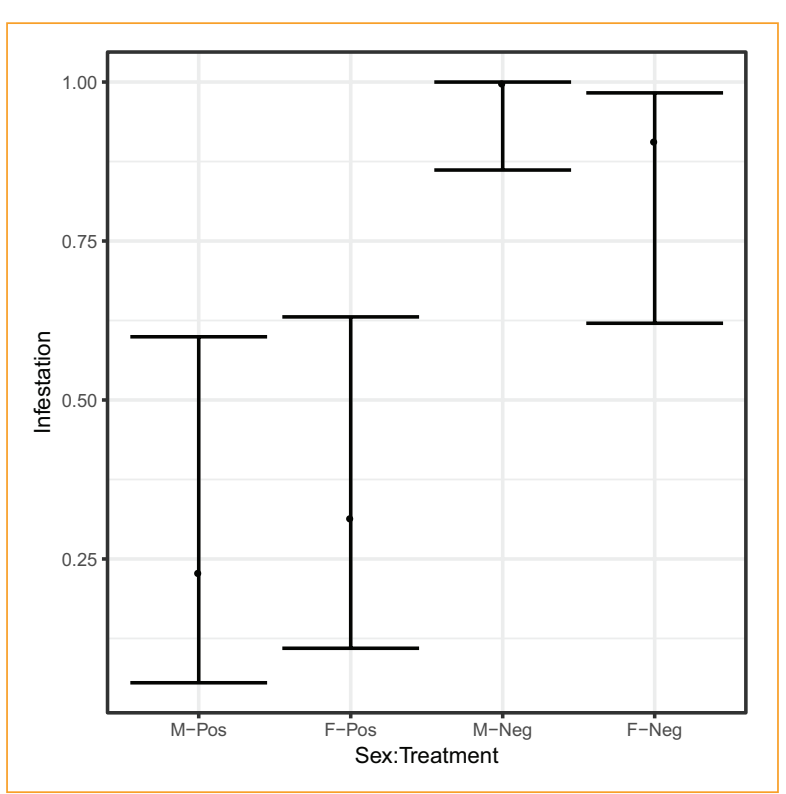

Figure 3. Effects display for the generalized linearmixed model of infestation. The points correspond to the probabilities estimated by the model and the bands denote $95 \%$ confidence intervals.

by $D$. folliculorum is present in a high percentage of hair follicles of the eyelashes in patients older than seventy years.

In contrast to this trend, the results of this group of patients diagnosed with glaucoma treated with prostaglandin analogues showed a low prevalence of $D$. folliculorum infestation (36.4\%). The results demonstrated, under the marginal approach and the GLMM, a clear effect of the treatment in the reduction of infestation and number of mites between the two groups analyzed in the study $(p<0.0001)$. In addition, the average of mites per eyelash in the group of patients with cataract was 3 (range 0-14); in the second group of patients with glaucoma was of 0.78 (range 0-5). Among infested patients in the cataract group, $49 \%(n=35)$ had a 


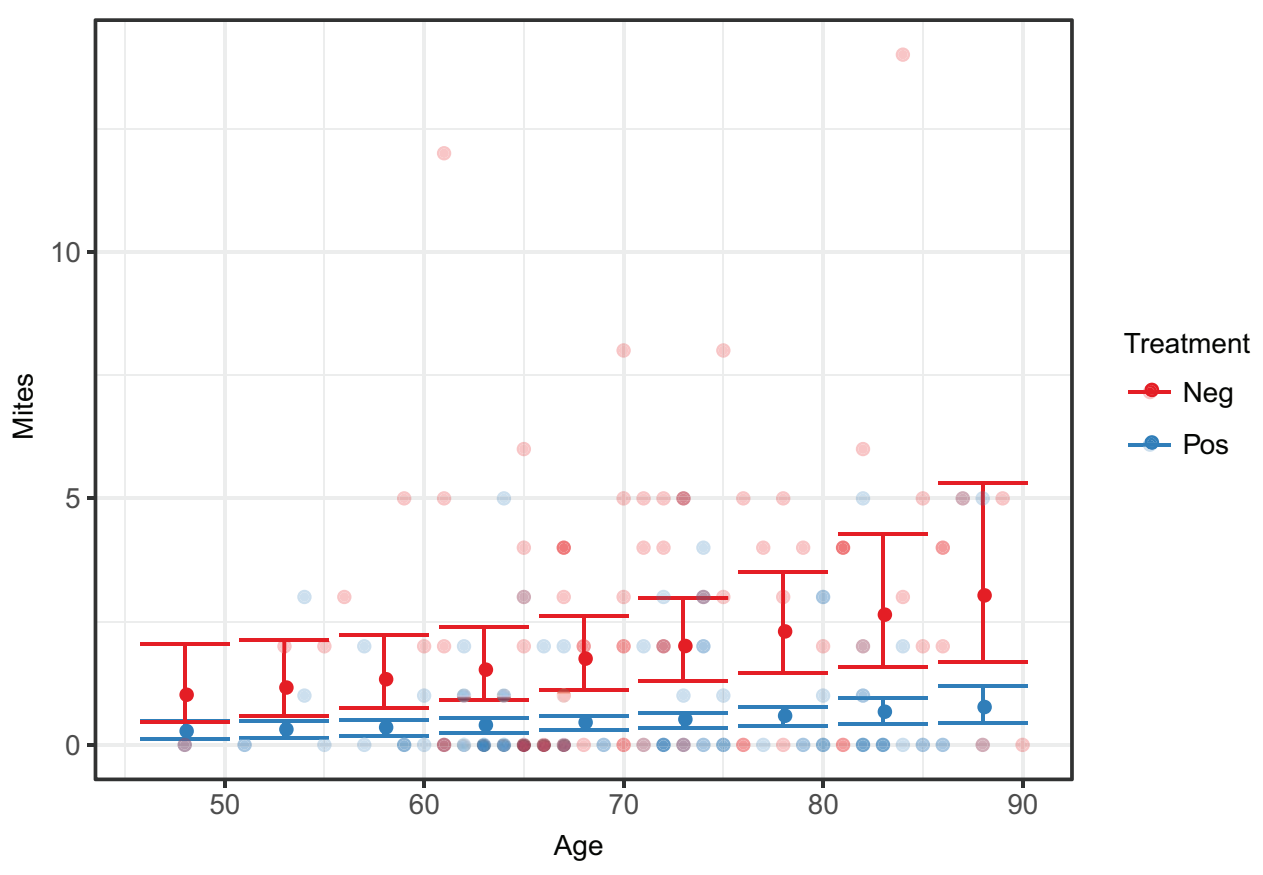

Figure 4. Effects display for the generalized linear mixed model of number of mites. The dense points and bars correspond to the model predictions with their respective $95 \%$ confidence intervals. The clear points correspond to study observations.

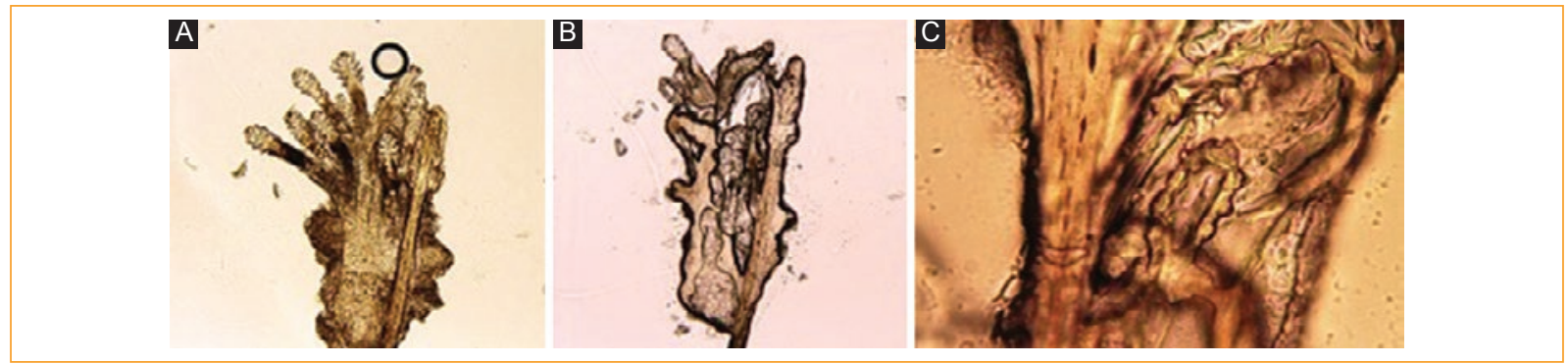

Figure 5. A: mites with cluster appearance prior to the instillation of a travoprost drop. B: twenty-two hours after contact with the travoprost drop. C: twenty-two hours after contact with a bimatoprost drop (photographs authored by Dr. F. Polit).

minimum of 4 mites; in the glaucoma group, $15 \%$ $(n=6)$. By slit-lamp examination, the presence of cylindrical dandruff at the base of the eyelashes is considered pathognomonic of $D$. folliculorum infestation. In a previous study, Gao, et al. ${ }^{7}$, defined it as diffuse if it involved more than ten eyelashes, and sporadic if there was less than ten eyelashes involved, according to the number of cylindrical dandruff present in the upper eyelid ${ }^{7}$. In this group of patients with glaucoma, the presence of cylindrical dandruff was scarce and in all of them considered as sporadic.
D. folliculorum are vermiform ectoparasites that lodge in hair follicles during daylight hours, but at night, they surface to reproduce. Since they have negative phototaxis, they must return to the interior of the hair shaft at dawn ${ }^{13}$. The low prevalence of $D$. folliculorum infestation in this group could be related to the fact that the instillation of prostaglandin analogues is nocturnal, which would allow contact with the parasites. In a previous study, Gao, et al. tested the effect of different substances on D. folliculorum and analyzed their survival after 150 minutes. Antiseptics and drugs such as 50\% 
shampoo for children, $100 \%$ mineral oil, $10 \%$ alcohol, $10 \%$ iodopovidone and $4 \%$ pilocarpine were not able to kill the parasites. In contrast, $100 \%$ alcohol eliminated them in less than five minutes ${ }^{14}$. In our in vitro study, we observed that all the mites survived at least 180 minutes after applying the different prostaglandin analogues drops. However, as the hours passed by, the morphological degradation suffered by the mites was much more noticeable than when a drop of saline was used, as was observed in the group of patients with cataracts. It should be added that the three commercial presentations used in this in vitro study contain benzalkonium chloride as a preservative; therefore, we cannot exclude its participation in the accelerated decomposition experienced by the parasites. On the other hand, it is likely that the exposure time used in the in vitro study was insufficient to kill the ectoparasites, which under the light microscope is recognized by the cessation of movement of the mite's legs, according to the specification of Gao. The permanence of the mites on the margin of the eyelids and in their immediate surroundings would allow a longer contact with the prostaglandin analogues compared to 180 minutes in the vitro study, in which all Demodex survived.

Prostaglandin analogues prolong the anagen phase of the growth cycle of the eyelashes, causing their lengthening. It has also been observed that they induce increased eyelash thickness and darkening. This thickness increase would narrow the hair follicle and make it more difficult for the Demodex to lodge and move (Fig. 6). In this study, the average infestation per eyelash was 0.78 and only $15 \%$ of those infested had at least four mites. No case was recorded with an excessive presence of Demodex, which could be related to the lack of space in the hair follicle for the lodging of the vermiform mites.

Within the limitations, it is recognized that our in vitro study does not discriminate if the effect observed in the parasites is caused by the prostaglandin analogue or by benzalkonium chloride, a preservative included in the commercial presentations used in this sample. Previous studies have confirmed the participation of benzalkonium chloride in the induction of ocular surface inflammation, allergic responses, fibrosis, punctate keratitis and dry eye syndrome, especially in patients who require continuous medication ${ }^{15}$. However, there are no clinical studies indicating that this quaternary ammonium derivative is capable of decreasing the prevalence of eyelid infestation by D. folliculorum. It would be useful to perform a new in vitro study to evaluate if $0.0015 \%$ tafluprost, a recent preservative-free prostaglandin analogue, is capable of

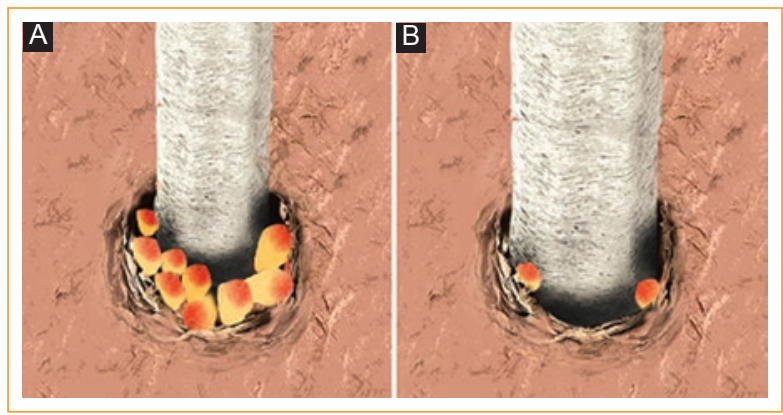

Figure 6. A: Several Demodex inside the hair follicle.

B: thickening of the eyelash and few Demodex inside the hair duct (images authored by Dr. F. Pólit).

causing morphological changes in mites similar to those documented in this study.

On the other hand, it is unknown if the low prevalence of mites would disappear when suspending the medication.

It would be interesting to perform a new study in patients infested with $D$. folliculorum and treat them with prostaglandin analogues.

It should be emphasized that although one of the limitations is the relatively small sample, it is compensated with its strengths, such as the use of high sensitivity and specificity diagnostic procedures, high-resolution microscopic equipment and new staining techniques, in order to achieve exact results regarding the evaluation of this population.

\section{Conclusion}

The use of prostaglandin analogues may reduce $D$. folliculorum infestation on the eyelashes.

\section{Ethical disclosures}

Protection of human and animal subjects. The authors declare that the procedures followed were in accordance with the regulations of the relevant clinical research ethics committee and with those of the Code of Ethics of the World Medical Association (Declaration of Helsinki).

Confidentiality of data. The authors declare that they have followed the protocols of their work center on the publication of patient data.

Right to privacy and informed consent. The authors have obtained the written informed consent of the patients or subjects mentioned in the article. The corresponding author is in possession of this document. 


\section{Conflict of interest}

\section{The authors declare no conflicts of interest.}

\section{References}

1. Foster PJ, Buhrmann R, Quigley HA, John GJ. The definition and classification of glaucoma in prevalence surveys. Br J Ophthalmol. 2002;86: 238-42.

2. Quigley HA, Broman AT. The number of people with glaucoma worldwide in 2010 and 2020. Br J Ophthalmol. 2006;90:262-7.

3. Johnstone MA. Hypertrichosis and increased pigmentation of eyelashes and adjacent hair in the region of the ipsilateral eyelids of patients treated with unilateral topical latanoprost. Am J Ophthalmol. 1997;124(4): 544-7.

4. Johnstone MA, Albert DM. Prostaglandin-induced hair growth. Surv Ophthalmol. 2002;47 Suppl 1:S185-202.

5. Morris CL, Stinnett S, Woodward J. The role of bimatoprost eyelash ge in chemotherapy-induced madarosis: an analysis of efficacy and safety. Int Trichology. 2011;3(2):84-91

6. Norn MS. Incidence of Demodex folliculorum on skin of lids and nose. Acta Ophthalmologica. 1982;60:575-83.
7. Gao YY Di Pascuale MA, Li W, Liu DT, Baradaran-Rafii A, Elizondo A, et al. High prevalence of ocular Demodex in lashes with cylindrical dandruffs. Invest Ophthalmol Vis Sci. 2005;46:3089-94.

8. Galvis-Ramírez V, Tello-Hernández A, Álvarez-Osorio L, Rey-Serrano JJ. Prevalencia de infección por Demodex folliculorum en pacientes que acuden a consulta general de oftalmología. Rev Salud Pública (Bogotá). 2011;13(6):990-7.

9. Pólit F, Pólit A, Soria J. Riesgo en la cirugía de catarata por infestación palpebral de Demodex folliculorum y su prevalencia, revisión de la técnica diagnóstica. Rev Mex Oftalmol. 2016;90(6):261-7.

10. McCulloch CE, Searle S.R, Neuhaus J.M. Generalized, Linear, and Mixed Models. 2.a ed. Wiley, EE.UU.; 2008.

11. Bates D, Maechler M, Bolker B, Walker S.(2015). Fitting Linear MixedEffects Models Using Ime4. J Statistical Software. 2015;67(1):1-48.

12. R Core Team. R: A language and environment for statistical computing R Foundation for Statistical Computing, Vienna, Austria; 2016. URL Disponible en: https://www.R-project.org/.

13. Corredor-Osorio R, Nava Castañeda A, Tovilla Canales JL-Tovilla y Pomar JL, Muñoz Salas S. Blefaritis por Demodex folliculorum. Rev Fac Med UNAM. 2000;43(4):125-9

14. Gao YY,Di Pascuale MA, Li W, Baradaran-Rafii A, Elizondo A Kuo CL, et al. In vitro and in vivo killing of ocular Demodex by tea tree oil. $\mathrm{Br} \mathrm{J}$ Ophthalmol. 2005;89(11):1468-73.

15. Baudouin C. Allergic reaction to topical eye drops. Curr Opin Allergy Clin mmunol. 2005:5:459-63. 